\title{
HUBUNGAN ANTARA NEUROLOGICAL SOFT SIGN DENGAN INTELLIGENCE QUOTIENT PADA ANAK USIA 8-9 TAHUN
}

\author{
ASSOCIATION BETWEEN NEUROLOGICAL SOFT SIGN AND IQ IN 8-9 YEARS OLD
}

\author{
Lani Satiyani, * Siti Aminah, * Paulus Anam Ong*
}

\section{ABSTRACT}

Introduction: Neurological soft signs (NSS) are common findings in developing children and tend to disappear as the child grows up. Their persistence into later years correlate with motor and cognitive development disturbance.

Aim: To examine the relationship between NSS and intelligence quotient (IQ) in 8-9 years old children in Bandung.

Methods: This analytic observational case control study was conducted in elementary school children in Bandung from May to July 2017. The case group is defined as subject with NSS score $\geq 7$, while controls are those with NSS score $<7$. Neurological soft signs was assessed with Gillberg method and IQ (original, full scale, performance, and performance) was assessed with Wechsler Intelligence Scale for Children (WISC)-III. Statistical analyses were performed to find the relationship between NSS and IQ score.

Results: Sixty eight subjects, majority were male (61.76\%) with median age 8.8 (8-9) years old took part in the study. Case group had lower mean score of IQ significantly. Subjects with higher NSS score had risk of having having lower full scale and performance IQ 4.94 and 11.20 times compared to subjects with lower NSS. There was an inverse correlation between NSS score and organizational IQ.

Discussion: Subjects retaining neurological soft sign have the possibility of having lower IQ compared to subjects without NSS.

Keyword: Children, intelligence quotient, neurological soft sign

\section{ABSTRAK}

Pendahuluan: Neurological soft sign (NSS) sering ditemukan pada anak dalam masa tumbuh kembang dan menghilang dengan bertambahnya usia. Menetapnya NSS pada usia tertentu berhubungan dengan gangguan perkembangan motorik dan fungsi kognisi. Bandung.

Tujuan: Mengetahui hubungan antara NSS dengan nilai intelligence quotient (IQ) anak usia 8-9 tahun di kota

Metode: Penelitian observasi analitik dengan desain kasus kontrol pada anak sekolah dasar di kota Bandung pada bulan Mei sampai Juli 2017. Kelompok kasus adalah subjek dengan skor NSS $\geq 7$, sedangkan kontrol adalah subjek dengan skor NSS $<7$. Pemeriksaan NSS menurut metode Gillberg, sedangkan kecerdasan anak berdasarkan IQ menggunakan Wechsler Intelligence Scale for Children (WISC)-III. Dilakukan uji statistik untuk mencari hubungan antara NSS dengan IQ.

Hasil: Didapatkan 68 subjek yang mayoritas laki-laki $(61,76 \%)$ dengan median usia 8,8 $(8-9,9)$ tahun. Kelompok kasus memiliki nilai rerata IQ lebih rendah dibandingkan dengan kontrol secara bermakna. Subjek dengan skor NSS tinggi mempunyai kemungkinan sebesar 4,94 dan 11,20 kali untuk memiliki skor full scale IQ (FSIQ) dan performance IQ (PIQ) yang lebih rendah dibandingkan subjek dengan NSS rendah. Terdapat korelasi negatif yang bermakna antara skor NSS dengan organizational IQ (OIQ).

Diskusi: Subjek dengan neurological soft sign yang menetap memiliki kemungkinan nilai IQ yang lebih rendah dari pada yang tanpa gejala NSS.

Kata kunci: Anak, intelligence quotient, neurological soft sign

*Departemen Neurologi FK Universitas Padjajaran/RSUP Dr. Hasan Sadikin, Bandung. Korespondensi: laniarsyad@gmail.com.

\section{PENDAHULUAN}

Neurological soft sign (NSS) adalah kelainan neurologis minor yang terutama dapat dilihat pada performa motorik dan bukan merupakan tanda adanya kelainan fokal pada otak ataupun suatu karakteristik akibat kondisi neurologis yang spesifik. ${ }^{1-3}$ Neurological soft sign mencerminkan adanya ketidakmatangan otak yang menyebabkan gangguan koneksi antara daerah kortikal dengan subkortikal atau antar daerah kortikal yang menyebabkan gangguan fungsi otak. ${ }^{1}$

Gejala dan tanda NSS dapat ditemukan pada anak dalam masa tumbuh kembang dan menghilang dengan bertambahnya usia seiring dengan tingkat kematangan otak. ${ }^{1-4}$ Menetapnya NSS pada usia tertentu tidak hanya menunjukkan adanya 
gangguan perkembangan motorik, namun sering dikaitkan dengan berbagai kelainan neurokognitif dan neuroanatomi, dan merupakan tanda adanya defek pada integrasi neuronal. ${ }^{2-6}$ Evaluasi NSS pada masa perkembangan sangat penting untuk menilai adanya gangguan perkembangan motorik sejak dini, termasuk perkembangan kognisi. ${ }^{3}$

Hambatan dan gangguan perkembangan pada sistem motorik akan memengaruhi perkembangan fungsi kognisi, begitu juga sebaliknya. ${ }^{7}$ Adanya koaktivasi beberapa area otak yang sama, terutama korteks prefrontal, ganglia basalis, dan serebelum pada saat melakukan beberapa tugas motorik dan kognisi tertentu menjadi landasan adanya hubungan antara performa motorik dengan kognisi. ${ }^{8-9}$

Di kota Bandung, pada tahun 2016 diketahui bahwa 37 dari 259 (14,3\%) anak sekolah berusia 7-8 tahun mengalami gangguan kontrol motorik yang ditunjukkan dengan skor NSS yang lebih tinggi dibandingkan anak lain seusianya. Tidak diketahui apakah tingginya skor NSS atau gangguan kontrol motorik ini disertai dengan adanya gangguan kognisi pada anak-anak tersebut atau tidak. ${ }^{10}$

Kemampuan kognitif merupakan berbagai keterampilan yang membentuk tingkat intelektual seseorang. Cara terbaik mengukur fungsi ini adalah menggunakan kombinasi tes yang terstandarisasi yaitu tes intelligent quotient (IQ). ${ }^{11}$ Alat skrining yang paling sering digunakan untuk mengevaluasi kemampuan intelektual anak adalah Wechsler Intelligence Scale for Children (WISC). Tes ini memeriksa aspek fungsi kognisi secara luas terhadap anak sekolah usia 6 tahun sampai 16 tahun 11 bulan. ${ }^{12}$

Wechsler Intelligence Scale for Children memiliki reliabilitas subtes moderate-excellent (6092), konsistensi indeks dan skor very good-excellent (80-97), serta stabilitas koefisien subtes adekuat pada 353 anak. Secara sederhana, interpretasi pemeriksaan WISC berdasarkan banyaknya skor dan aspek yang dapat diselesaikan dengan baik oleh anak, yang terdiri dari full scale (FSIQ), verbal (VIQ), performance (PIQ), dan original IQ (OIQ). ${ }^{12}$

\section{TUJUAN}

Untuk mengetahui hubungan antara NSS dengan intelligence quotient (IQ) pada anak sekolah dasar usia 8-9 tahun.

\section{METODE}

Penelitian ini merupakan suatu penelitian observasi analitik dengan rancangan studi kontrol kasus pada anak sekolah dasar berusia 8-9 tahun di kota Bandung, bulan Mei sampai Juli 2017. Seluruh subjek diambil berdasarkan data hasil penelitian sebelumnya mengenai profil NSS pada anak sekolah usia 7-8 tahun di kota Bandung. ${ }^{10}$ Subjek yang diikutsertakan dalam penelitian ini adalah anak sekolah dasar berusia 8 sampai 9 tahun yang memiliki skor NSS $\geq 7$ untuk kelompok kasus dan NSS $<7$ untuk kelompok kontrol, bersedia untuk diperiksa, dan mendapatkan izin dari orang tua.

Anak yang menunjukkan adanya hard neurological sign pada saat pemeriksaan, riwayat palsi serebral, infeksi selaput otak, tumor otak dan trauma kepala serta tidak kooperatif dieksklusi dari penelitian ini. Neurological soft sign diperiksa berdasarkan metode Gillberg oleh peneliti dan IQ diperiksa dengan menggunakan WISC-III oleh tim Psikologi Klinis Anak Universitas Padjadjaran, Bandung.

Selama periode waktu penelitian, dari 37 anak yang menunjukkan skor NSS tinggi (NSS $\geq 7$ ) pada penelitian sebelumnya, ${ }^{10}$ didapatkan 34 anak yang memenuhi kriteria inklusi sebagai kelompok kasus dan diikutsertakan dalam penelitian ini. Sebagai kelompok kontrol, diambil 34 subjek dengan skor NSS normal (NSS $<7$ ) yang sesuai usia dan jenis kelaminnya dengan subjek pada kelompok kasus, sehingga jumlah total subjek pada penelitian ini adalah 68 anak. Karakteristik subjek penelitian antara kelompok kasus dan kontrol dibuat homogen agar dapat dilakukan analisis statistik lebih lanjut.

Penelitian ini telah mendapatkan persetujuan dari Komisi Etik Penelitian Kesehatan Fakultas Kedokteran Universitas Padjadjaran nomor 525/ UNG.C.10/PN/2017. Data yang terkumpul dikelompokkan, diedit, dan diproses dengan menggunakan program SPSS versi 20 Windows. Analisis bivariat dilakukan dengan uji $\mathrm{t}$ berpasangan, besarnya hubungan diukur dengan rasio Odds (RO), dilakukan juga penghitungan koefisien korelasi untuk melihat arah dan kekuatan korelasi. 
Tabel 1. Karakteristik Subjek Penelitian $(n=68)$

\begin{tabular}{|c|c|c|c|c|}
\hline \multirow[b]{2}{*}{ Variabel } & \multirow[b]{2}{*}{ Total } & \multicolumn{2}{|c|}{ Kelompok } & \multirow[b]{2}{*}{$\mathbf{p}$} \\
\hline & & $\begin{array}{l}\text { Kasus } \\
(n=34)\end{array}$ & $\begin{array}{c}\text { Kontrol } \\
(n=34)\end{array}$ & \\
\hline $\begin{array}{l}\text { Usia } \\
\text { - Rerata }( \pm \mathrm{SD}) \\
\text { - Median (rentang nilai) }\end{array}$ & $\begin{array}{c}8,87 \pm 0,52 \\
8,80(8-9,90)\end{array}$ & $8,85(8-9,90)$ & $8,75(8-9,80)$ & $0,542 *$ \\
\hline $\begin{array}{l}\text { Jenis kelamin } \\
\text { - Laki-laki } \\
\text { - Perempuan }\end{array}$ & $\begin{array}{l}42(61,76 \%) \\
26(38,24 \%)\end{array}$ & $\begin{array}{l}21(61,76 \%) \\
13(38,24 \%)\end{array}$ & $\begin{array}{l}21(61,76 \%) \\
13(38,24 \%)\end{array}$ & $1,000 * *$ \\
\hline $\begin{array}{l}\text { Pendidikan anak } \\
\text { - Kelas } 3 \\
\text { - Kelas } 4\end{array}$ & $\begin{array}{l}44(64,71 \%) \\
24(35,29 \%)\end{array}$ & $\begin{array}{l}21(61,76 \%) \\
13(38,24 \%)\end{array}$ & $\begin{array}{l}23(67,65 \%) \\
11(32,35 \%)\end{array}$ & $0,612 * *$ \\
\hline $\begin{array}{l}\text { Pendidikan ayah } \\
\text { - } \leq 9 \text { tahun } \\
\text { - }>9 \text { tahun }\end{array}$ & $\begin{array}{l}18(26,57 \%) \\
50(73,53 \%)\end{array}$ & $\begin{array}{c}7(20,59 \%) \\
27(79,41 \%)\end{array}$ & $\begin{array}{l}11(32,35 \%) \\
23(67,65 \%)\end{array}$ & $0,272 * * *$ \\
\hline $\begin{array}{l}\text { Pendidikan ibu } \\
-\leq 9 \text { tahun } \\
\text { - }>9 \text { tahun }\end{array}$ & $\begin{array}{l}19(27,94 \%) \\
49(72,06 \%)\end{array}$ & $\begin{array}{c}8(23,53 \%) \\
26(76,47 \%)\end{array}$ & $\begin{array}{l}11(32,35 \%) \\
23(67,65 \%)\end{array}$ & $0,417 * * *$ \\
\hline $\begin{array}{l}\text { Penghasilan orang tua } \\
\text { - }<2,8 \text { juta } \\
\text { - } \quad \geq 2,8 \text { juta }\end{array}$ & $\begin{array}{l}46(67,65 \%) \\
22(32,45 \%)\end{array}$ & $\begin{array}{c}25(73,53 \%) \\
9(26,47 \%)\end{array}$ & $\begin{array}{l}21(61,76 \%) \\
13(38,24 \%)\end{array}$ & $0,300 * *$ \\
\hline
\end{tabular}

*Uji Wilcoxon; **Uji Chi-square; ***Uji Kolmogorov Smirnov dan Fisher Exact; NSS: Neurological Soft Sign.

Tabel 2. Hasil Pemeriksaan NSS dan IQ pada Kedua Kelompok (n=68)

\begin{tabular}{|c|c|c|c|c|}
\hline \multirow[b]{2}{*}{ Variabel } & \multirow[b]{2}{*}{ Total } & \multicolumn{2}{|c|}{ Kelompok } & \multirow[b]{2}{*}{$\mathbf{p}$} \\
\hline & & $\begin{array}{l}\text { Kasus } \\
(n=34)\end{array}$ & $\begin{array}{c}\text { Kontrol } \\
(n=34)\end{array}$ & \\
\hline NSS Median (rentang nilai) & $6(0-11)$ & $7(7-11)$ & $3(0-5)$ & $<0,005^{*}$ \\
\hline OIQ (Rerata \pm SD) & $107,60 \pm 13,60$ & $102,79 \pm 14,66$ & $112,41 \pm 10,63$ & $0.006^{* *}$ \\
\hline FSIQ (Rerata \pm SD) & $97,50 \pm 10,82$ & $92,70 \pm 9,53$ & $102,29 \pm 9,98$ & $<0,005 * *$ \\
\hline PIQ (Rerata \pm SD) & $93,39 \pm 11,36$ & $90,47 \pm 7,05$ & $103,12 \pm 10,12$ & $<0,005^{* *}$ \\
\hline VIQ (Rerata \pm SD) & $96,79 \pm 10,75$ & $96,06 \pm 12,42$ & $100,73 \pm 9,82$ & $0,022 * *$ \\
\hline
\end{tabular}

*Uji Wilcoxon; **Uji t berpasangan; NSS: Neurological Soft Sign; OIQ: Original Intelligence Quotient; FSIQ: Full scale Intelligence Quotient; PIQ: Perfornance Intelligence Quotient; VIQ: Verbal Inteligence Quotient.

\section{HASIL}

Terdapat 68 subjek yang mayoritas laki-laki $(61,76 \%)$ berusia median 8,8 (8-9,9 tahun). Tidak didapatkan adanya perbedaan karakteristik subjek penelitian yang bermakna antara kelompok kasus dengan kontrol yang menunjukkan bahwa kedua kelompok sama atau homogen, sehingga layak untuk dilakukan uji statistik lebih lanjut (Tabel 1).

Terdapat perbedaan bermakna skor NSS dan IQ antara kelompok kasus dengan kontrol (Tabel 2).
Kelompok kasus memiliki nilai rerata IQ yang lebih rendah secara signifikan dibandingkan kelompok kontrol pada tiap domainnya (OIQ, FSIQ, PIQ, dan VIQ). Walaupun demikian, rerata skor FSIQ pada kedua kelompok adalah $>90$ yang menunjukkan bahwa subjek pada penelitian ini mengerti dan memahami instruksi pada saat pemeriksaan NSS.

Tabel 3 menunjukkan hubungan yang bermakna antara tingginya nilai NSS dengan rendahnya IQ (FSIQ dan PIQ). Subjek dengan skor NSS $\geq 7$ 
(kelompok kasus) mempunyai risiko sebesar 4,94 dan 11,2 kali untuk memiliki skor FSIQ dan PIQ yang lebih rendah dibandingkan subjek dengan NSS $<7$ (kelompok kontrol).
Pada penelitian ini, subjek pada kelompok kasus lebih banyak anak laki-laki (61,76\%) dibandingkan perempuan, serupa dengan Engelsman $(62,12 \%)$ dan Kikkert $(62,57 \%) \cdot{ }^{13-14}$ Hal ini sesuai

Tabel 3. Hubungan antara NSS dengan IQ $(n=68)$

\begin{tabular}{|c|c|c|c|c|c|c|}
\hline \multirow{3}{*}{ Variabel } & \multicolumn{2}{|c|}{ Kelompok } & \multirow{3}{*}{$\mathbf{p}$} & \multirow{3}{*}{ RO } & \multirow{2}{*}{\multicolumn{2}{|c|}{ IK 95\% }} \\
\hline & \multirow{2}{*}{$\begin{array}{l}\text { Kasus } \\
(n=34)\end{array}$} & \multirow{2}{*}{$\begin{array}{c}\text { Kontrol } \\
(n=34)\end{array}$} & & & & \\
\hline & & & & & Lower & Upper \\
\hline OIQ (Rerata \pm SD) & $102,79 \pm 14,66$ & $112,41 \pm 10,63$ & 0,197 & 5,69 & 0,63 & 51,57 \\
\hline FSIQ (Rerata \pm SD) & $92,70 \pm 9,53$ & $102,29 \pm 9,98)$ & $0,033 *$ & 4,94 & 1,24 & 19,76 \\
\hline PIQ (Rerata \pm SD) & $90,47 \pm 7,05$ & $103,12 \pm 10,12$ & $0,001 *$ & 11,20 & 2,29 & 54,56 \\
\hline VIQ $($ Rerata \pm SD $)$ & $96,06 \pm 12,42$ & $100,73 \pm 9,82$ & 0,132 & 3,13 & 0,87 & 11,21 \\
\hline
\end{tabular}

Uji Fisher; RO: rasio Odds; IK: interval kepercayaan; OIQ: Original Intelligence Quotient; FSIQ: Full scale Intelligence Quotient; PIQ: Perfornance Intelligence Quotient; VIQ: Verbal Inteligence Quotient.

Didapatkan adanya korelasi yang bermakna (Tabel 4) dengan arah korelasi negatif antara skor NSS dengan OIQ, dengan kekuatan lemah ( $\mathrm{r}=-$ 0,296). Demikian pula, terdapat korelasi bermakna antara skor NSS dengan FSIQ dan PIQ dengan arah korelasi negatif dan kekuatan sedang $(\mathrm{r}=-0,428$ dan $-0,581)$. Hal ini menunjukkan semakin tinggi skor NSS, maka semakin rendah skor OIQ, FSIQ, dan PIQ.

\section{PEMBAHASAN}

Pada penelitian ini dipilih subjek yang berusia 8-9 tahun dengan median 8,8 (8-9,9) tahun. Usia tersebut serupa dengan penelitian Engelsman, yaitu rerata $8,9 \pm 1,9$ tahun ${ }^{13}$ dan Kikkert, $9 \pm 0,25$ tahun. ${ }^{14}$ Pemilihan ini berdasarkan teori bahwa NSS dapat ditemukan dan merupakan suatu yang normal pada anak dalam masa tumbuh kembang, dan berkurang dengan bertambahnya usia. ${ }^{15}$ Meskipun NSS biasanya tidak ditemukan pada usia 10 tahun, kemampuan motorik dasar sudah dikuasai pada saat usia 6 atau 7 tahun. Pada usia 9 tahun sebagian besar fungsi motorik dan praksis telah matang, ${ }^{16}$ sehingga diharapkan NSS yang ditemukan akan minimal. Pemilihan subjek juga dimaksudkan untuk dapat mendeteksi adanya gangguan perkembangan pada anak usia sekolah sedini mungkin.

Tabel 4. Korelasi antara Skor NSS dengan IQ $(n=68)$

\begin{tabular}{lcc}
\hline \multicolumn{1}{c}{ Skor NSS } & r & p \\
\hline Original IQ & $-0,296$ & $0,014^{*}$ \\
Full scale IQ & $-0,428$ & $<0,005^{*}$ \\
Performance IQ & $-0,581$ & $<0,005^{*}$ \\
Verbal IQ & $-0,190$ & 0,120 \\
\hline
\end{tabular}

IQ: inteligence quotient; Uji Korelasi Pearson; r: koefisien korelasi. dengan teori bahwa jenis kelamin berpengaruh terhadap performa motorik. Secara umum, anak perempuan menunjukkan performa motorik yang lebih baik dibandingkan laki-laki. Berdasarkan gambaran MRI, area otak yang mendasari perkembangan motorik (korteks lobus frontal dan parietal) pada perempuan mencapai ukuran maksimal 1 tahun lebih cepat daripada laki- laki. ${ }^{15}$

Pada penelitian ini tidak ada perbedaan pendidikan maupun status sosial ekonomi keluarga pada kedua kelompok. Sebagian besar orang tua subjek, baik ayah maupun ibu menempuh pendidikan lebih dari 9 tahun dan penghasilan rerata per bulan di bawah upah minimum kota Bandung $(<2,8$ juta rupiah). Dengan demikian, perbedaan kedua kelompok mungkin disebabkan oleh yang memengaruhi pola asuh dalam keluarga, seperti lingkungan tempat tinggal, budaya, dan kebiasaan keluarga.

Pada penelitian ini terdapat perbedaan yang bermakna skor IQ antara kelompok kasus dengan kontrol (Tabel 2). Skor IQ tersebut lebih rendah dibandingkan dengan Kikkert yang menggunakan Weschler Abreviate Scale of Intelligence (WASI) untuk tes IQ dan metode Touwen untuk performa motorik. Kikkert membagi subjek penelitian 3 kelompok; 1) anak normal, 2) anak dengan disfungsi motorik minor sederhana, dan 3) anak dengan disfungsi motorik minor yang kompleks. Kelompok 1 memiliki rerata skor FSIQ 104; PIQ 105; dan VIQ 102. Kelompok 2 dan 3 masing-masing memiliki rerata FSIQ 100; PIQ 100; VIQ 99; dan FSIQ 95; PIQ 95; VIQ 95. Semua rerata skor IQ tersebut 
masih dalam kisaran kategori IQ yang sama dengan penelitian ini.

Penelitian ini mendapatkan hubungan yang bermakna antara NSS dengan FSIQ dan PIQ dengan RO masing-masing 4,94 dan 11,2. Hal ini berarti bahwa anak dengan $\geq 7$ mempunyai risiko sebesar 4,94 dan 11,2 kali untuk memiliki skor FSIQ dan PIQ lebih rendah dibandingkan subjek dengan NSS $<7$. Walaupun tidak dapat dibandingkan secara langsung, penelitian Engelsman menunjukkan hasil yang serupa. Analisis regresi linier dengan performa motorik sebagai variabel terikat dan IQ sebagai prediktor, menunjukkan hasil bahwa setiap penurunan 1 SD poin IQ, didapatkan penurunan 10 persentil poin untuk performa motorik menurut Movement Assessment battery for Children (MABC). Hal ini berarti subjek dengan IQ yang rendah berisiko memiliki performa motorik yang lebih buruk. ${ }^{13}$

Penelitian ini juga menunjukkan korelasi yang bermakna antara NSS dengan OIQ ( $\mathrm{r}=-0,29$; $\mathrm{p}=0,014)$, FSIQ $(\mathrm{r}=-0,428 ; \mathrm{p}<0,005)$, dan PIQ ( $\mathrm{r}=-$ $0,581 ; \mathrm{p}<0,005)$. Korelasi negatif artinya semakin tinggi skor NSS, maka semakin rendah IQ. Dengan kata lain, semakin buruk performa motorik, semakin rendah IQ. Tidak ditemukannya hubungan maupun korelasi yang bermakna antara skor NSS dengan VIQ pada penelitian ini karena pemeriksaan NSS menurut Gillberg tersebut lebih menekankan pada performa motorik terutama praksis dan fungsi eksekutif. Metode ini tidak sensitif untuk fungsi bahasa, sehingga tidak berhubungan dengan VIQ.

Penelitian Kikkert menunjukkan hasil yang sejalan dengan penelitian ini. Full scale IQ dan PIQ pada anak dengan disfungsi motorik minor lebih rendah secara bermakna dibandingkan dengan anak normal, tanpa ada perbedaan skor VIQ antara kedua kelompok. ${ }^{14}$

Demikian pula Engelsman mendapatkan adanya korelasi antara skor IQ dengan performa motorik $(r=0,44 ; p<0,001)$, yaitu semakin rendah IQ semakin buruk performa motorik. Performa motorik diperiksa dengan menggunakan MABC, dan IQ diperiksa menggunakan WISC III, WISC IV, Wechsler Preschool and Primary Scale of Intelligence, Kaufman Assessment Battery for Children, Snijders-Oomen Non verbaIntelligence Test, dan Revise Amsterdamse
Kinder Intelligence Test. Skor IQ dikategorikan menjadi normal (85+), borderline (71-84), dan mild learning disability $(<70)$. Sebanyak $82 \%$ anak yang memiliki skor IQ $<85$ menunjukkan performa motorik yang buruk, ${ }^{13}$ namun tidak dijelaskan lebih lanjut korelasi antara performa motorik dengan OIQ dan PIQ.

Pemeriksaan NSS, selain melihat performa motorik dari segi keseimbangan, persistensi dan kecepatan, juga memeriksa fungsi eksekutif dan praksis yang memerlukan fungsi kognisi yang baik. Menetapnya NSS pada usia tertentu mencerminkan adanya gangguan perkembangan pada fungsi motorik yang seringkali berhubungan dengan gangguan perkembangan area lain termasuk neurokognitif. Hal ini didasari oleh teori adanya koaktivasi beberapa area otak yang sama, yaitu korteks prefrontal, ganglia basalis dan serebelum pada saat melakukan aktivitas motorik kompleks dan kognisi tertentu. Koaktivasi ini terjadi terutama pada saaat melakukan tugas yang sulit, baru, dan berubah polanya, sehingga membutuhkan konsentrasi dan respons yang cepat. Kedua, keterampilan motorik dan kognisi memiliki waktu perkembangan yang sama, dengan percepatan antara usia 5 dan 10 tahun. Ketiga, kedua fungsi ini sama-sama melalui proses perencanaan, memiliki urutan tertentu, dan memerlukan pemantauan. ${ }^{8}$

Keterbatasan penelitian ini adalah tidak dilakukan anamnesis mengenai pola asuh anak dalam keluarga dan pencapaian nilai akademis anak di sekolah, karena keterbatasan waktu penelitian. Pada penelitian ini tidak diteliti mengenai faktor internal dan eksternal lain yang memengaruhi performa motorik dan fungsi kognisi anak, seperti faktor genetik, status gizi, lingkungan tempat tinggal, dan besarnya stimulasi yang diberikan.

\section{DAFTAR PUSTAKA}

1. Gustafsson P, Svedin CG, Ericsson I, Linden C, Karlsson MK, Thernlund G. Reliability and validity of the assessment of neurological soft-signs in children with and without attention-deficit-hyperactivity disorder. Dev Med Child Neurol. 2010;52(4):364-70.

2. Kaneko M, Yamashita Y, Inomoto O, Iramina K. Soft neurological signs in childhood by measurement of arm movements using acceleration and angular velocity sensors. Sensors. 2015;15(10):25793-808.

3. Kaneko M, Yamashita Y, Iramina K. Quantitative 
evaluation system of soft neurological signs for children with attention deficit hyperactivity disorder. Sensors. 2016;16(1):116.

4. Martins IP, Lauterbach $M$, Luis $H$, Amaral $H$, Rosenbaum G, Slade PD, dkk. Neurological subtle signs and cognitive development: a study in late childhood and adolescence. Child Neuropsychol. 2013;19(5):466-78.

5. Neelam K, Garg D, Marshall M. A systematic review and meta-analysis of neurological soft signs in relatives of people with schizophrenia. BMC Psychiatry. 2011;11:139.

6. Hembram M, Simlai J, Chaudhury S, Biswas P. First rank symptoms and neurological soft signs in schizophrenia. Psychiatry J. 2014;2014:931014.

7. Diamond A. Interrelated and interdependent. Dev Sci. 2007;10(1):152-8.

8. Van-der-Fels IM, Wierike SC, Hartman E, ElferinkGemser MT, Smith J, Visscher C. The relationship between motor skills and cognitive skills in 4-16 year old typically developing children: A systematic review. J Sci Med Sport. 2015;18(6):697-703.

9. Njiokiktjien C. Functional neuroanatomy of motor and behavioural disorders. Developmental dyspraxias and related motor disorders; neural substrates and assessment. Amsterdam: Suyi Publications; 2007. h. 8-87.
10. Dessy, Aminah S, Amalia L. Profil soft neurological sign pada anak sekolah usia 7 dan 8 tahun di tiga sekolah dasar di kota Bandung [tesis]. Bandung: Universitas Padjadjaran; 2016.

11. Ortiz SO, Lella S, Canter A. Intellectual ability and assessment: a primer for parents and educators. National Association of School Psychologists. 2010. h. $1-4$.

12. Colman AM. Aspect of intelligence. Dalam: Roth I, editor. The open university's introduction to psychology. Lawrence Erlbaum Associates with the Open University; 1990. h. 323-72.

13. Smits-Engelsman B, Hill EL. The relationship between motor coordination and intelligence across the IQ range. Pediatrics. 2012;130(4):e950-6.

14. Kikkert HK, Jong DE, Hadders-Algra M. Minor neurological dysfunction and IQ in 9-year-old children born at term. Dev Med Child Neurol. 2011;53(4):e16-25.

15. Larson JC, Mostofsky SH, Goldberg MC, Cutting LE, Denckla MB, Mahone EM. Effects of gender and age on motor exam in typically developing children. Dev Neuropsychol. 2007;32(1):543-62.

16. Njiokiktjien C. Developmental dyspraxias and other motor disorders. Developmental dyspraxias and related motor disorders; neural substrates and assessment. Amsterdam: Suyi Publications; 2007. h. 176-262. 